\title{
Development of Caluromys philander (Didelphimorphia, Didelphidae) Foetuses with Estimated Ages of 20 and 25 days
}

Daiane Chaves Nascimento ${ }^{1}$, Phelipe Oliveira Favaron ${ }^{2 *}$, Jociel Ferreira Costa ${ }^{1}$, Elmary da Costa Fraga ${ }^{1}$, Maria Angelica Miglino $^{2}$ and Maria Claudene Barros ${ }^{1}$

${ }^{1}$ Laboratory of Genetics and Molecular Biology of the State University of Maranhao, Centre for Advanced Studies of Caxias, Maranhao, Brazil

${ }^{2}$ Department of Surgery, School of Veterinary Medicine and Animal Science, University of Sao Paulo, Sao Paulo, Brazil

\begin{abstract}
Background: Although Eutherian represents a higher-level taxon that includes all mammals except monotremes and marsupials, these two last groups especially the metatherians (marsupials) represent an important source of information on the evolution of the reproductive features in eutherian mammals. The aim of the present study was to describe the macroscopic and microscopic morphological features of Caluromys philander foetuses at two estimated developmental stages: 20 and 25 days of age.
\end{abstract}

Methods: Twelve foetuses were obtained from two females and according to the Crown-rump lengths they were allocated in two Groups (Group I=about 20 days and Group II=about 25 days). The weight was also determined. After fixation in $70 \%$ ethanol or $10 \%$ formalin the specimens were examined by means of gross morphology and the external features were photo-documented. After that, the samples were dehydrated using increasingly concentrated ethanol solutions (70 to $100 \%)$, cleared in xylene, and embedded in paraplast. The paraffin blocks were sliced into $5 \mu \mathrm{m}$ thick sections and the slides were stained using haematoxylin and eosin and Masson's trichrome. Descriptive data were organised according to the body regions: cranial, thoracic, and abdominal.

Results: Specimens from Group I showed more premature features, such as a more pronounced cervical curvature, than those in Group II. In addition, individuals from both groups exhibited more developed forelimbs than hind limbs. In relation to the cranial region, in both stages the retina was pigmented, but in Group II the ocular globe, the external ear and the eyelid projection were more prominent, as were the emergence of a row of hair on the eyelids and the presence of a darkened strip of hair between the eyes. Histological analysis showed that in Group II the skull bones were more calcified than in the Group I. In both groups, there was only a small opening in the mouth to allow for attachment to the nipples. The tongue was a well-developed organ and the onset of teeth formation was only visible in histological sections. Heart and lungs were observed in the thoracic region and they were composed by typical cells, structures, and layers. They were protected by the rib cage, which was undergoing ossification leading to rib formation. The organs inside the abdominal region mainly related to the digestory system (liver, stomach, and intestinal loops), as well as the kidney showed similar characteristics in relation to the stage of development and cellular composition between the two groups. The sexes in both groups were distinguished through the external genitalia.

Conclusion: The results showed that at approximately 20 to 25 days of development, C. philander foetuses still present macroscopic features typical of preterm individuals. However, the vital organs required for survival in the external environment have formed and are able to perform their normal functions.

Keywords: Marsupialia; Metatheria; Embryology; Brazilian marsupials

\section{Introduction}

The differences in the reproductive patterns of Prototheria, Metatheria and Eutheria resulted of different evolutionary responses to the stresses of the environment during the mammals evolution. Especially the metatherians or marsupials, represent an important source of information on the evolution of reproductive features in the eutherian mammals, as they show a primitive placenta referred to as the choriovitelline placenta [1-4].

Metatherian embryos present a short intrauterine life and are born in an embryonic stage [5]. However, this stage is compensated by a prolonged period of parental care, which for the most members of the order Marsupialia (about $50 \%$ of the species) begins in an external abdominal pouch, which form a true marsupium, while in others it can be formed by a simple fold of skin or as occur in a few number of species that lack any type of marsupium [6]. In the didelphids, the period of pregnancy is less than 14 days, and maternal care can last for up to a year $[7,8]$.
Among Neotropical marsupials, the family Didelphidae is the most diversified and currently comprises 95 species and 19 genera [9]. There are two distinguished subfamilies in this group: the Didelphinae and the Caluromyinae. The Caluromyinae include the genus Caluromys, represented by three species, among which only one (C. derbianus) is not found in Brazil [10]. The species C. philander (Figure 1A), a medium-sized arboreal marsupial, shows a wide geographic distribution in South America, occurring in the Amazonia, Atlantic

*Corresponding author: Favaron PO, Surgery Department, School of Veterinary Medicine and Animal Science, University of Sao Paulo. Av. Prof. Dr. Orlando Marques de Paiva 87, Sao Paulo, SP, Brazil, Tel/Fax: (55)-11-30917690; E-mail: phelipe.favaron@yahoo.com.br

Received March 18, 2013; Accepted April 18, 2013; Published April 22, 2013

Citation: Nascimento DC, Favaron PO, Costa JF, da Costa Fraga E, Miglino MA, et al. (2013) Development of Caluromys philander (Didelphimorphia, Didelphidae) Foetuses with Estimated Ages of 20 and 25 days. J Cytol Histol 4 : 172. doi:10.4172/2157-7099.1000172

Copyright: (c) 2013 Nascimento DC, et al. This is an open-access article distributed under the terms of the Creative Commons Attribution License, which permits unrestricted use, distribution, and reproduction in any medium, provided the original author and source are credited. 

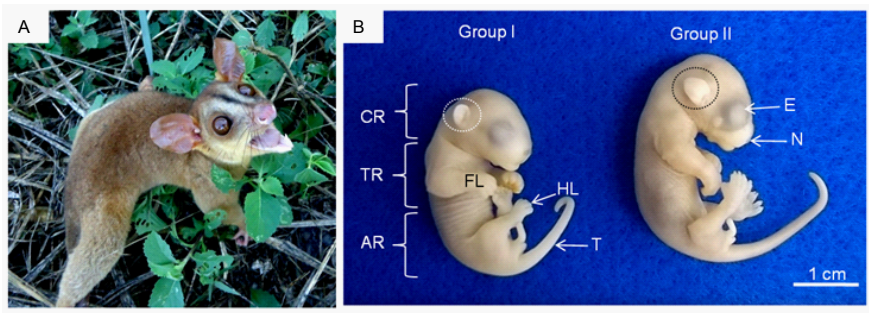

Figure 1: A: Adult specimen of C. philander (Didelphidae). In B: Macroscopic comparison of the developmental stages and external morphological features of foetuses from Groups I and II. Note the division of the main body regions into the cranial region (CR), thoracic region (TR) and abdominal region. In the cranial region, an eye $(\mathrm{E})$ with a pigmented retina, an external ear (circle) and the nasal region $(\mathrm{N})$ can be observed. The forelimbs $(\mathrm{FL})$, hindlimbs $(\mathrm{HL})$ and an elongated tail $(\mathrm{T})$ can also be seen.

Forest, Cerrado (savannah-like grasslands) and Pantanal (floodplain grasslands) biomes $[9,11,12]$.

Studies aimed at characterising the reproductive biology of the didelphid marsupials have been reviewed by [13]. These studies address general topics such as the oestrous cycle, female reproductive tract anatomy, development in the marsupium, litter size and breeding season. There are few studies on the embryonic and foetal development of marsupials. Regarding these aspects, Monodelphis domestica and Didelphis virginiana are the best-studied species among the Didelphidae. The craniofacial and neurologic ontogenetic features of $M$. domestica and some features of the intra- and extra-uterine developmental stages of $D$. virginiana are the main characteristics that have been reported [14-19].

The species C. philander has been little studied in terms of its embryology, and only general aspects of the reproductive biology of this genus are described in the literature [20,21]. In addition a study investigating the ontogeny of the ear bones [18] among other marsupials the authors studied the didelphids M. domestica and C. philander.

Considering the lack of ontogenetic studies involving didelphids in Brazil and the importance of data on their embryology for understanding not only the reproductive and evolutionary features of this group but also those of the eutherian mammals, this current study aimed to describe the morphological features of newborn C. philander foetuses during their development in individuals with estimated ages of 20 and 25 days.

\section{Materials and Methods}

\section{Biometric data and macroscopic description}

Totally, 12 foetuses of $C$. philander in two different gestational stages were obtained in the Laboratory of Genetics and Molecular Biology of the State University of Maranhão (Universidade Estadual do Maranhão-UEMA), Centre for Advanced Studies of Caxias (Centro de Estudos Superiores de Caxias-CESC) in Maranhão-MA, Brazil and were analysed in the School of Veterinary Medicine and Animal Science, University of Sao Paulo, Sao Paulo, Brazil. Samples were obtained under the authorisation of the Brazilian Institute of the Environment and Renewable Natural Resources (Instituto Brasileiro do Meio Ambiente e dos Recursos Naturais Renováveis-IBAMA) (Process number 25746-1).

The foetuses had been fixed in either $70 \%$ ethanol or a $10 \%$ buffered formalin solution.
The foetuses were examined and allocated into two Groups (Group I: $n=6$, about 20 days, which was collected at the end of October and Group II: $n=6$, about 25 days of development, collected at the beginning of November). Initially, foetuses were measured using a stainless steel calliper to determine the crown-rump length (CR) [22]. The head was measured with the nuchal crest as a reference at one extremity and the last sacral vertebra at the opposite extremity. The weight (g) was determined using a digital scale (0.001 g-BEL ENGINEERING) [15].

In order to obtain a better understanding of the dynamics and chronology of the development of $C$. philander, foetuses were examined macroscopically for description of the external features according to the body regions: cranial, thoracic, and abdominal (Figure 1B). For a more detailed analysis, a dissecting microscope (Zeiss Stemi SV6, Germany) was used, and macroscopic features were photo-documented (Machine Sony MVC-CD500) against a black or blue background.

The nomenclature was based on the guidelines of the International Committee on Veterinary Gross Anatomical Nomenclature, International Committee on Veterinary Histological and Embryological Nomenclature [23-25].

\section{Light microscopy}

After the macroscopic descriptions fixed foetuses from the two Groups were subjected to histological procedures. First the foetuses were washed in phosphate buffer or distilled water to remove the fixative, followed by dehydration in a series of increasing ethanol concentrations ( 70 to $100 \%$ ) for 1 hour in each, diaphanisation for 1 hour in xylene and embedding in a paraffin-type medium [26]. Then, the paraffin blocks were subjected to microtomy using an automatic microtome (Leica RM2165), and 5- $\mu$ m sections were obtained. The sections were adhered to slides and left in an oven at $60^{\circ} \mathrm{C}$. Finally, the slides were stained with hematoxylin and eosin and Masson's trichrome $[26,27]$.

\section{Results}

\section{General macroscopic description}

The offspring of the first female displayed a CR length of between 2.63 and $2.92 \mathrm{~cm}(2.76 \pm 0.11 \mathrm{~cm})$ and weighed between $1.62-1.90 \mathrm{~g}$ $(1.73 \pm 0.11 \mathrm{~g})$, while in Group II, the CR length was between 2.87 and $3.11 \mathrm{~cm}(2.95 \pm 0.08 \mathrm{~cm})$, and the weight ranged from $2.07-2.34 \mathrm{~g}(2.21$ $\pm 0.09 \mathrm{~g})$ (Table 1$)$.

The individuals in Group I showed a relative cervical curvature when compared with individuals of Group II, while the latter group displayed a more elongated body with a special emphasis on the nasal region and the forelimbs and hindlimbs. An elongated and curved tail was also a feature observed in these stages (Figure 1B)

In addition, the whole body of the foetuses was covered by hair that was short and slightly pigmented.

\section{Cranial region}

In Group I, in which the individuals were at approximately 20 days of age, well-formed upper and lower lips and a short nasal region were identified on the face. The eyes displayed a pigmented retina and an evident eyelid projection (Figure 2A). In both stages, the retina was pigmented, but in Group II (estimated age of 25 days), the ocular globe, the external ear and the eyelid projection were more prominent, as were the emergence of a row of hair on the eyelids and the presence of a darkened strip of hair between the eyes, which is a feature typical 
Citation: Nascimento DC, Favaron PO, Costa JF, da Costa Fraga E, Miglino MA, et al. (2013) Development of Caluromys philander (Didelphimorphia, Didelphidae) Foetuses with Estimated Ages of 20 and 25 days. J Cytol Histol 4: 172. doi:10.4172/2157-7099.1000172

\begin{tabular}{|c|c|c|c|c|}
\hline \multicolumn{2}{|c|}{ Collection number } & Length (cm) & Weight (g) & $\begin{array}{c}\text { Estimated } \\
\text { age (days) }\end{array}$ \\
\hline \multirow{5}{*}{ Group I } & DCN38-1 & 2.78 & 1.74 & 20 \\
\cline { 2 - 5 } & DCN38-2 & 2.63 & 1.60 & 20 \\
\cline { 2 - 5 } & DCN38-3 & 2.79 & 1.62 & 20 \\
\cline { 2 - 5 } & DCN38-4 & 2.92 & 1.90 & 20 \\
\cline { 2 - 5 } & DCN38-5 & 2.82 & 1.72 & 20 \\
\cline { 2 - 5 } & DCN38-6 & 2.63 & 1.80 & 20 \\
\hline \multirow{5}{*}{ Group II } & $2.76 \pm 0.11$ & $1.73 \pm 0.11$ & 25 \\
\cline { 2 - 5 } & DCN41-7 & 3.11 & 2.16 & 25 \\
\cline { 2 - 5 } & DCN41-8 & 2.92 & 2.07 & 25 \\
\cline { 2 - 5 } & DCN41-9 & 2.90 & 2.17 & 25 \\
\cline { 2 - 5 } & DCN41-10 & 2.96 & 2.27 & 25 \\
\cline { 2 - 5 } & DCN41-11-12 & 2.87 & 2.34 & \\
\hline & & 2.99 & 2.24 & \\
\hline \multirow{4}{*}{} & & $2.95 \pm 0.08$ & $2.21 \pm 0.09$ & \\
\hline
\end{tabular}

Table 1: Material collected and values for fetal length $(\mathrm{cm})$, fetal weight $(\mathrm{g})$, and estimated age (according to Evans and Sack, 1973) of fetuses of Caluromys philander (Marsupiallia: Didelphimorphia)
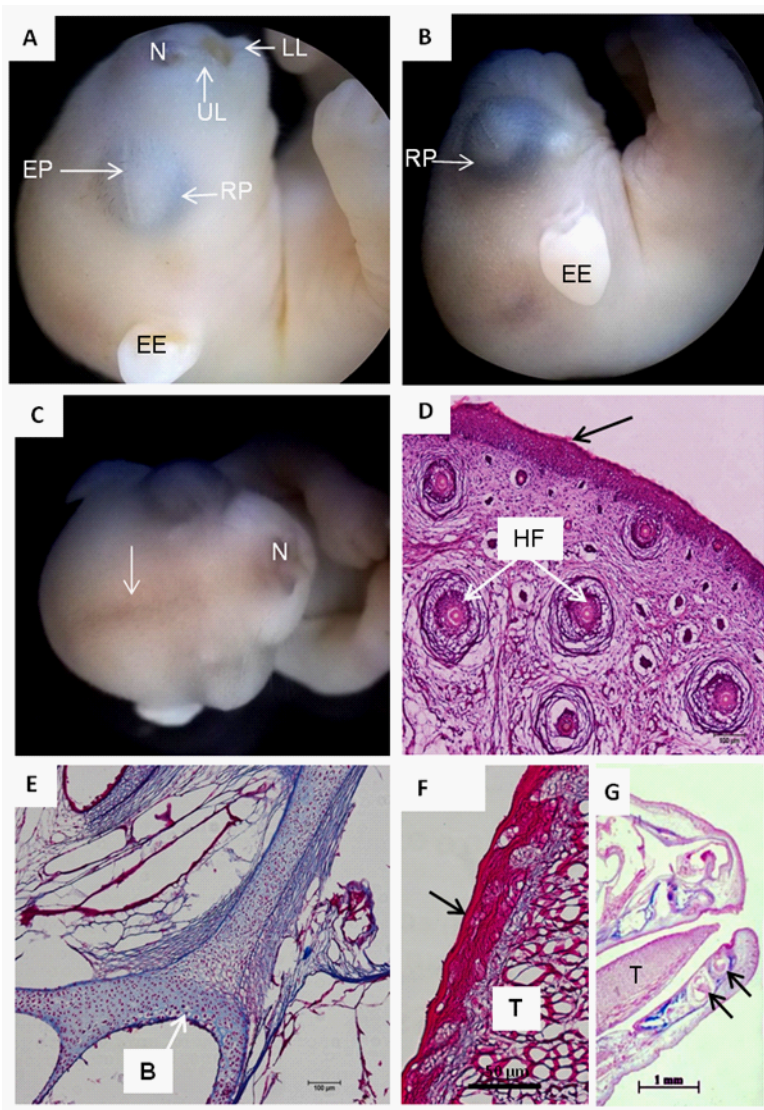

Figure 2: Morphology of the cranial region of $C$. philander (Didelphidae) foetuses. In A: Individual from Group I; and in B-D: Group II. In A: In the ora cavity region, note the upper lip (UL) and lower lip (LL), the short nasal region $(\mathrm{N})$, the eyes with retinal pigmentation (RP), eyelid projection (EP) and a short external ear (EE). In B-D: Note an increase of the ocular globe and of retinal pigmentation (RP) as well as the length of the external ear (EE). The formation of a darkened strip of hair (arrow) extending from the nasal region (N) to the frontal region. D: Note an increase in the number of hair follicles (HF) near to the nasal region, as was a thin layer of keratin (arrow) on the dermal epithelium. Staining: hematoxylin and eosin. In E, Note the ossification process of the bones of the skull base (B) in Group II; in F, note the keratinised stratified epithelium (arrow) of the tongue ( $T$ ); and in $G$, note the alveolar region of the teeth (arrows). Staining: Masson's trichrome. of adults (Figures $2 \mathrm{~B}$ and $\mathrm{C}$ ). Hair was particularly abundant in the nasal plane region, and in Group II, the sensory hairs on the face and the vibrissae were even more developed, as observed in the histological analysis (Figures 2C and D).

When the individuals in the two groups were compared, it was noted through histology that in Group II (Figure 2E) the bones that composed the skull were in a more calcified stage than was observed in the Group I, once in this Group were observed predominantly chondrocytes cells forming the skull cap (data not shown).

In both groups, there was only a small opening in the mouth to allow for attachment to the nipples (Figure 2A). The tongue was a welldeveloped organ composed of striated skeletal muscle, and in Group I, it displayed a thin layer of keratin on the epithelium (Figure 2F). The onset of teeth formation was only visible in histological sections (Figure $2 \mathrm{G}$ ), and teeth eruption was not detected in the oral cavity at either of the examined ages (Groups I and II).

\section{Thoracic region}

Developed organs such as the heart and lungs were observed in the thoracic region. They were protected by the rib cage, which was undergoing ossification leading to rib formation (Figures $3 \mathrm{~A}$ and $3 \mathrm{~B}$ ).

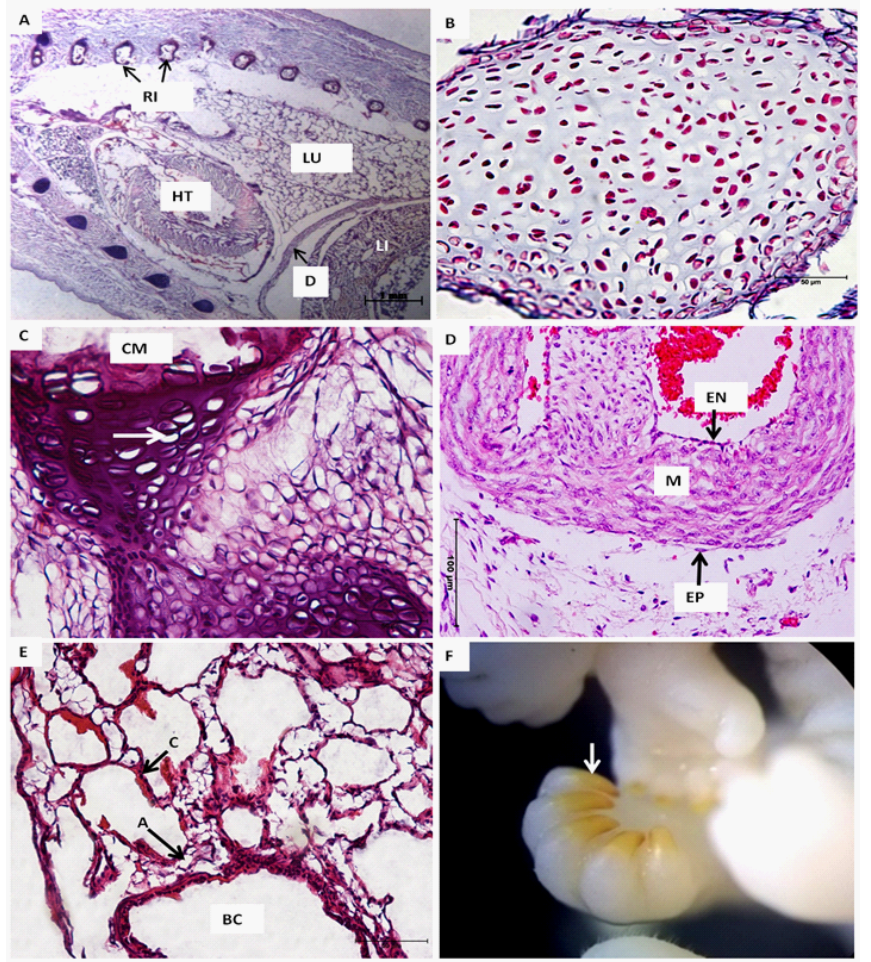

Figure 3: Morphology of the thoracic region of C. philander (Didelphidae) foetuses. A: Note the syntopy of the heart (HT) and lungs (LU) in the thoracic cavity in an individual from Group I. The ribs (RI) undergoing ossification can also be observed in the cross-sections. The diaphragm (D) separates the thoracic and abdominal cavities. $\mathrm{LI}=$ liver. B: In Group I, the bone moulds are still predominantly formed by cartilaginous tissue. C: Histological section of the ribs in individual from Group II showing the process of calcification occurring in these bones. Note the mature chondrocytes (arrow) and the region of calcified matrix (CM). D: In both groups, the heart displayed the three typical layers: the endocardium (EN), myocardium (M) and epicardium (EP). E: The lungs of both groups consisted of parenchyma with a large number of alveoli $(A)$ in close contact with blood capillaries $(C) . B C=$ bronchiole. $F$ : Detail of the keratinised claws (arrow). Staining: hematoxylin and eosin. 
When the ossification process taking place in the ribs and vertebrae was compared between the two groups, more intense ossification was identified in the individuals of Group II, where the presence of mature chondrocytes and a calcifying matrix were observed in these bones (Figure 3C).

In both of the analysed stages, the heart showed the typical cell layers constituting the wall of the organ. The myocardium represented the thickest muscle layer of the heart, and it was composed of fusiform cells arranged in bundles, forming cardiac striated muscle. Internally, lining the heart and in direct contact with the blood cells, there was a layer of squamous epithelium over a layer of connective tissue, forming the endocardium, which was in contact with the cardiac chambers. Externally, the heart was surrounded by the epicardium and a thin layer of serosal tissue (Figure 3D), which was closely associated with the pericardial cavity.

Similar to the heart, the lungs in both Groups had formed. These organs comprised an alveolar parenchyma with a large number of bronchi and bronchioles, with the latter structures branching into different calibres (Figure 3E).

In individuals from Group I and II, the diaphragm was formed by striated skeletal muscle with a concave shape (Figure 3A), the anterior portion of which was connected to the xiphoid process of the sternum and the posterior portion to the lumbar vertebrae. The diaphragm separated the thoracic cavity from the abdominal cavity.

In both Groups, the forelimbs were in an advanced stage of development (Figure 1B). Their cornified structures, such as the claws, were elongated and sharp, and exhibited a darker coloration due to the keratinisation process. The digits were completely separated, and interdigital membranes were not identified (Figure 3F).

\section{Abdominal region}

In both Groups (I and II) the organs inside the abdominal region mainly related to the digestory system showed similar characteristics in relation to the stage of development and cellular composition.

The liver was the largest organ in the abdominal cavity and was bordered by the diaphragm in its most cranial portion (Figures $3 \mathrm{~A}$ and $4 \mathrm{~A}$ ). Due to the darkened colour of the liver because of the large amount of blood present in its parenchyma and the transparency of the foetuses skin, the contours of the liver could be observed inside the abdominal cavity. Histologically, the liver was composed of hepatocytes with large nuclei and a small amount of cytoplasm, which were arranged into cords. Blood vessels of various calibres were observed in the parenchyma of this organ (Figure 4B).

The stomach and intestinal loops were also observed in histological sections. The stomach was a hollow organ with thin wall muscle in the pups, and the intestinal loops presented epithelial projections forming long villi, which are responsible for increasing the surface area for absorption (Figure 4A, 4C and 4D). The definitive kidneys (metanephros) were also identified.

It was possible to distinguish the sexes in both groups through the external genitalia. In females, the emergence of the mammary glands and the beginning of the formation of abdominal folds forming a rudimentary marsupium were observed (Figure 4E). In males, the testicles were clearly visible in the inguinal region (Figure 4F). Part of the umbilical cord was still present in both analysed gestational periods (Figure 4E).
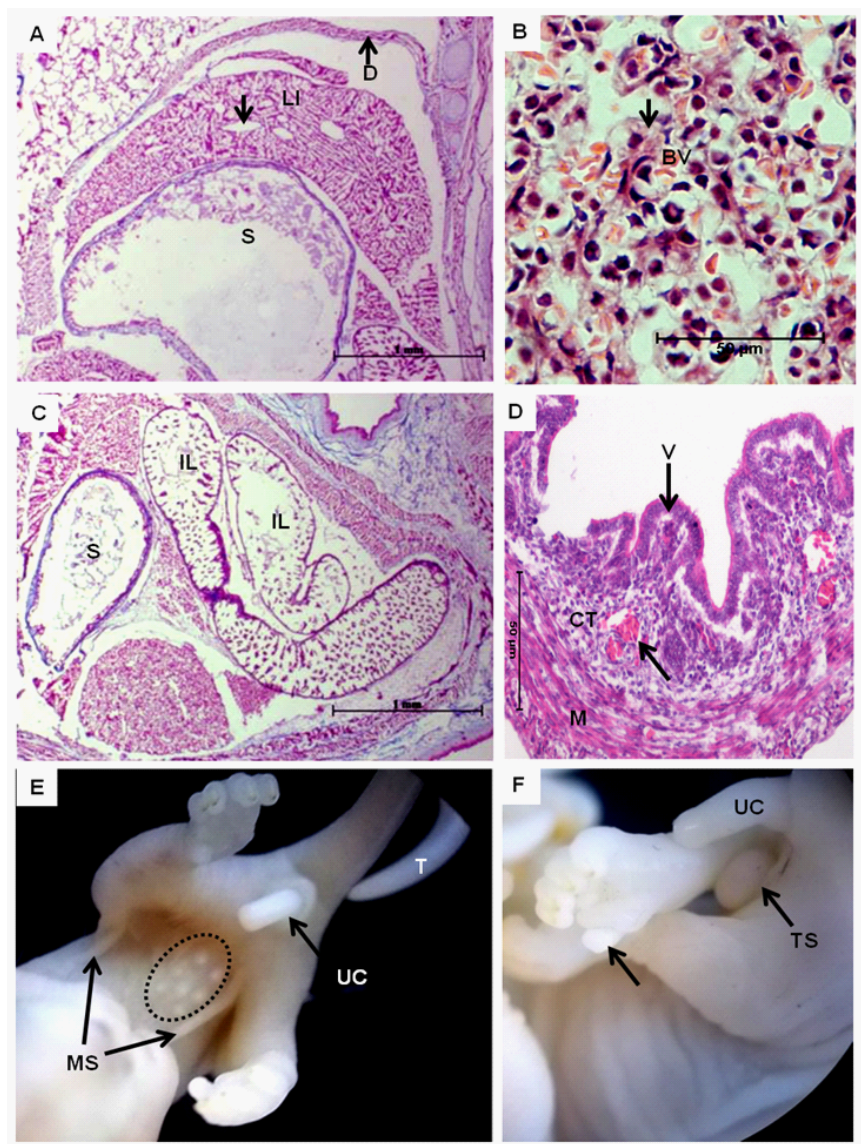

Figure 4: Morphology of the abdominal region in C. philander (Didelphidae) foetuses from Groups I and II. In A: Syntopy of the diaphragm (D) bordering the abdominal cavity, liver (LI) and stomach (S). B: Detail of the cords of hepatocytes (arrow) surrounded by blood vessels (BV) in the liver parenchyma. In C: Note the syntopy of the stomach (S) and the intestinal loops (IL), which project into the intestinal lumen, forming the villi. In D: Note the layers of the intestinal wall formed by the villi $(\mathrm{V})$ of the intestinal epithelium, connective tissue (CT) containing blood vessels (arrow) and muscle layers (M). Staining: hematoxylin and eosin. In E and F: Differentiation of the external genitalia In females of both groups, the development of the marsupium (MS) and mammary glands (circle) was noted, and in males, the testicles (TS) were evident in the inguinal region. $\mathrm{T}=$ depigmented tail, $\mathrm{UC}=$ umbilical cord, and arrow $=$ opposable thumb.

The hind limbs were much less well developed than the forelimbs regarding both their size and cornified structures, such as the claws. A remarkable feature of the examined stages was the presence of an opposable thumb, which is characteristic of arboreal animals (Figure $4 \mathrm{~F})$. The tail was elongated and was clearly bigger in the individuals from Group II (Figure 1B). Macroscopically, it was noted that the tail was depigmented in its most distal portion (Figure 4E), as in adults.

\section{Discussion}

The Methateria share many aspects with the Eutheria. However, they exhibit significant differences regarding their modes of reproduction, which represent alternative forms of adaptation that have occurred during the evolution of mammals. Thus, description of the ontogenetic features of marsupials is essential to achieve a biological understanding of this group.

Clark and Smith [19] confirmed the hypothesis that newborn marsupials display a conservative morphology; i.e., at birth, the pups of 
marsupials from America and Australia are at the same developmental stage. However, after birth, the emergence of features varies according to the species, which shows the importance of describing the features of C. philander in the analysed stages.

According to [13] the average number of foetuses produced in each pregnancy for the species C. philander varies from 3 to 6 individuals, according to the latitude, and females in the reproductive stage can be observed during August to November, especially during the spring season in South America, which corroborates with the findings of the present study. For the species D. virginiana, [28] recorded an average of 8 pups per litter, and the two annual breeding seasons suggested for specimens from the United States occur between January and September.

According to [29] at birth, the forelimbs of the marsupial $M$. domestica are in a more advanced stage of development than the hind limbs. This statement corroborates with the data obtained for $C$. philander from both Groups (I and II), as there was a clear difference observed in the development of the fore- and hindlimbs, with the forelimbs showing claws that were more keratinised and sharper than those of the hindlimbs as a consequence of rapid development. Krause and Krause [30] concluded that $91 \%$ of brain development in Didelphis occurs after the attachment of pups to the nipples inside the marsupial pouch, and the brain initially only exhibits basic functions related to the coordination of forelimbs.

The mouth of $D$. virginiana opossum embryos is first observed as a wide opening and closes gradually as the end of the pregnancy approaches, leaving only a small circular opening that will be used for pups to attach to the nipples [13]. In addition, the lips do not fully open until after 50 days of age [14]. These findings are in agreement with the results of the present study, where a central opening between the lips was noted in both groups, and the pups were strongly attached to the nipples, confirming their prematurity and need for the maternal presence.

Organs related to suction in marsupials are also expected to develop more rapidly to exert their functional requirements. The tongue, which is used in the process of sucking breast milk, was found to be one of the most well-developed organs in both analysed groups, corroborating the results reported in the literature [13,19].

Between 11 and 17 days after delivery, it is possible to distinguish the sexes of individuals externally in specimens from the genus Didelphis. Males display scrotal sacs, while females exhibit the contours of a marsupium and rudimentary nipples [15]. These same features were observed in males and females in both examined stages (20 and 25 days of development) in C. philander.

On day 35 after birth, the pups may display soft hair, which is visible through a hand lens, and the vibrissae begin to grow [15]. These features were observed in both examined stages, with the individuals in Group II exhibiting a greater amount of hair and longer vibrissae. These results reveal that $C$. philander initiates hair and vibrissae development at an earlier developmental stage than species from the genus Didelphis [15].

According to Monteiro-Filho and Cáceres [13] and Hartman [14] in the genus Didelphis, the eye opening and teeth eruption do not occur until approximately 60 days after birth, and these features were not observed in the current analysis. The eyes in both stages were closed, but eyelid opening had progressed further in Group II than in
Group I. Although the onset of tooth formation was visualised during the microscopic analysis, tooth eruption was not observed in the oral cavity.

The species C. philander exhibits arboreal habits, and opposable thumbs and a prehensile tail are typical features associated with this type of adaptation [10]. In both analysed groups, these features were observed to be developing, with differences noted according to the different stages. The depigmentation of the distal portion of the tail is another characteristic found in adults that was visualised in individuals from Group II, which showed a more advanced stage of development.

\section{Conclusions}

The results obtained in the present study revealed that at approximately 20 to 25 days of development, C. philander pups still present typical features of premature individuals. However, vital organs for survival in the external environment have developed and are able to perform their normal functions at this time. The lack of data regarding the embryology of didelphid marsupials makes it more difficult to recognise their embryonic features, and the data generated in the present study are therefore fundamental to complement future embryological studies for this group.

\section{Acknowledgements}

We thank the technical support from several members of GENBIMOL (Laboratory of Genetics and Molecular Biology, Caxias, Maranhao, Brazil) during the collect of the samples. This research was supported by grants from FAPEMA (Fundacao de Amparo a Pesquisa e ao Desenvolvimento Científico e Tecnologico do Maranhao).

\section{References}

1. Smith KK (1997) Comparative Patterns of Craniofacial Development in Eutherian and Metatheria Mammals. Evolution 51: 1663-1678.

2. Freyer C, Zeller U, Renfree MB (2003) The marsupial placenta: a phylogenetic analysis. J Exp Zool A Comp Exp Biol 299: 59-77.

3. Hickman CP, Roberts LS, Keen SL, Larson A, L'Anson H, et al. (2008) Integrated Princinples of Zoology: (14thEdn.)

4. Renfree MB (2010) Review: Marsupials: placental mammals with a difference Placenta 31: S21-26.

5. Freyer C, Zeller U, Renfree MB (2007) Placental function in two distantly related marsupials. Placenta 28: 249-257.

6. Vaughan TA, Ryan JM, Czaplewski NJ (2011) Mammalogy. Massachusetts, Jones and Bartlett Publishers, USA.

7. Smith KK (2001) The evolution of mammalian development. Bull Mus Comp Zool 156: 119-135.

8. Smith KK (2006) Craniofacial development in marsupial mammals: developmental origins of evolutionary change. Dev Dyn 235: 1181-1193.

9. Gardner AL (2008) Mammals of South America. Vol. 1. Marsupials, Xenarthrans Shrews, and Bats. Chicago University Press, USA

10. Reis NR, Peracchi AL, Pedro WA, Lima IP (2006). Mamíferos do Brasil Londrina, SEMA, USA.

11. Costa JC, Nascimento DC, Santos LLL, Olímpio APM, Fraga EC, et al. (2012) Pequenos mamíferos não voadores de ocorrência na Área de Proteção Ambiental Municipal do Inhamum, Caxias/MA, p.117-130. In: Barros MC (2012) Biodiversidade na Área de Proteção Ambiental Municipal do Inhamum. Maranhão, UEMA.

12. Paglia AP, Fonseca GAB, Rylands AB, Herrmann G, Aguiar LMS, et al. (2012) Lista Anotada dos Mamíferos do Brasil. Arlington, Conservation Biology.

13. Monteiro-Filho ELA, Cáceres NC (2006) Biologia Reprodutiva de fêmeas de marsupiais didelfídeos. In: Ibids. (Eds), Os marsupiais do Brasil: Biologia ecologia e evolução. Campo Grande, UNIDERP. 
Citation: Nascimento DC, Favaron PO, Costa JF, da Costa Fraga E, Miglino MA, et al. (2013) Development of Caluromys philander (Didelphimorphia, Didelphidae) Foetuses with Estimated Ages of 20 and 25 days. J Cytol Histol 4: 172. doi:10.4172/2157-7099.1000172

14. Hartman CG (1928) The breeding season of the opossum (Didelphis virginiana) and the rate of intrauterine and postnatal development. J Morphol 46: 143-215.

15. Petrides GA (1949) Sex and age determination in the opossum. J Mammal 30 364-378.

16. Nievelt AFH, Smith KK (2005) Tooth eruption in Monodelphis domestica and its significance for phylogeny and natural history. J Mammal 86: 333-34.

17. Vaglia JL, Smith KK (2003) Early differentiation and migration of cranial neura crest in the opossum, Monodelphis domestica. Evol Dev 5: 121-135.

18. Sánchez-Villagra MR, Gemballa S, Nummela S, Smith KK, Maier W (2002) Ontogenetic and phylogenetic transformations of the ear ossicles in marsupial mammals. J Morphol 251: 219-238.

19. Clark CT, Smith KK (1993) Cranial osteogenesis in Monodelphis domestica (Didelphidae) and Macropus eugenii (Macropodidae). J Morphol 215: 119-149.

20. Biggers JD (1967) Notes on reproduction of the wooly opossum (Caluromys derbianus) in Nicaragua. J Mammal 48: 678-680.

21. Perret M, Atramentowicz M (1989) Plasma concentrations of progesterone and testosterone in captive woolly opossums (Caluromys philander). J Reprod Fertil 85: 31-41.

22. Evans HE, Sack WO (1973) Prenatal development of domestic and laboratory mammals: growth curves, external features and selected references. Zentralbl Veterinarmed C 2:11-45.
23. International Committee on Veterinary Embriologycal Nomenclatura (1994) Nomina embryological, (2nd edn.) Rev. Zurich: International Committee on Veterinary Embriological Nomenclatura (Together with Nomina Anatomica Veterinaria, (4th edn.) and Nomina Embriologica Veterinaria).

24. International Committee on Veterinary Gross Anatomical Nomenclatura (1994) Nomina Anatomica Veterinaria, (4th edn.) Zurich: International Committee on Veterinary Gross Anatomical Nomenclatura (Together with Nomina Histológica, (2nd edn.), and Nomina Embriologica Veterinaria.

25. International Committee on Veterinary Histological Nomenclatura (1994) Nomina histologica, (2nd edn.) Rev. Zurich: International Committee on Veterinary Histological Nomenclatura (Together with Nomina Anatomica Veterinaria, (4th edn.) and Nomina Embriologica Veterinaria)

26. Tolosa EMC, Rodrigues CJ, Behemer AO, Freitas-Neto AG (2003) Manual de Técnicas para Histologia Normal e Patológica.

27. Lillie RD, Fulmer HM (1976) Histopathologic technique and pratical histochemistry.

28. Reynolds HC (1945) Some aspects of the Life History and Ecology of the Opossum in Central Missouri. J Mammal 26: 361-379.

29. Martin KEA, Mackay S (2003) Postnatal development of the fore- and hindlimbs in the grey short-tailed opossum, Monodelphis domestica. J Anat 202: 143-152.

30. Krause WJ, Krause WA (2006) The opossum: Its amazing story. Department of Pathology and Anatomical Sciences, School of Medicine University of Missouri, Columbia, USA. 